\title{
Analysis of Desert Sand Dune Migration Patterns from Landsat Image Time Series for The Southern California Desert
}

\section{Potter $\mathrm{C}^{1^{*}}$ and Weigand $\mathrm{J}^{2}$}

${ }^{1}$ NASA Ames Research Center, Biospheric Science, Moffett Field, CA, USA

${ }^{2}$ Bureau of Land Management (BLM), United States Department of the Interior, Sacramento, CA, USA

*Corresponding author: Potter C, NASA Ames Research Center, Biospheric Science, Moffett Field, CA, USA, Tel: 6506046164; E-mail: chris.potter@nasa.gov

Rec date: Apr 22, 2016; Acc date: May 09, 2016; Pub date: May 16, 2016

Copyright: (C) 2016 Potter C, et al. This is an open-access article distributed under the terms of the Creative Commons Attribution License, which permits unrestricted use, distribution, and reproduction in any medium, provided the original author and source are credited.

\begin{abstract}
Developers of renewable energy installations in southern California need to evaluate the risks to facility operations from proximity to active desert dunes. This study first validated Landsat image spectral data using ground-based data collection of aeolian sand migration rate measurements surveyed in Arizona as an accurate method for characterizing dune mobility. The predominant direction of measured sand dune movements was correctly mapped at this site from the satellite imagery, as well as the migration distances of the leading edges of sand dunes over the entire 1992-2010 monitoring period. Application of the Landsat image method to two dune systems in southern California demonstrated its usefulness for mapping sand migration patterns and rates. Between 1995 and 2014, Palen Dunes lost over half of its stable dune surface and increased its sand accumulation zone by nearly that same area coverage. In contrast, changes in the sand movement patterns at Kelso Dunes were not apparent, perhaps due in to its more constraining mountain landscape features. These results have an immediate application for understanding future sand transport and characterizing potential impacts to nearby utility-scale solar energy installations.
\end{abstract}

Keywords: Sand dune; Migratio; Landsat; Palen dunes; Kelso dunes

\section{Introduction}

Dune systems occur extensively in the desert southwest region of the United States. Their dynamics differ greatly, ranging from highly active to virtually stationary. Individual dune systems can have unique movement characteristics because the environmental forces that shape the areal extent and composition of dunes are themselves acting in unique combinations. Factors influencing dune mobility include wind transport capacity, sand supply, sand particle size distribution (sand availability), the extent of surface stabilization by vegetation cover, and overall moisture balance in the dune [1-3].
For the past 20 years, studies of the geomorphology of desert sand dunes relied mainly on field measurements of wind flow and sand flow over individual dunes [3]. However, ground-based approaches can rarely cover large areas of dune movements. Modeling methods have been shown to complement field-based approaches [4] and automated approaches using remote sensing to track dune movement are emerging [5,6]. The combined use of remote sensing imagery and long-term global positioning system (GPS) measurements has enabled the accurate mapping of large dune area movements (Table 1).

\begin{tabular}{|l|l|l|}
\hline Field survey & Global positioning system (GPS) and ground-based LiDAR (light detection and ranging) Redsteer et al. [7] \\
\hline Modeling approaches & $\begin{array}{l}\text { Werner [8] modeled the development of dune field patterns. Kocurek and Ewing [9] described non-linear modeling to examine sand dunes } \\
\text { as self-organized complex systems. Hardware in wind tunnels was used in the modeling. }\end{array}$ \\
\hline \multirow{2}{*}{ Remote sensing } & Aerial photography & Historical records \\
\cline { 2 - 3 } & Optical imagery & $\begin{array}{l}\text { Advanced Very High Resolution Radiometer (AVHRR), Landsat TM imagery, ASTER, SPOT, } \\
\text { Quickbird [4] }\end{array}$ \\
\cline { 2 - 3 } & Radar detection & Spaceborne Imaging Radar (SIR-C), Radarsat, and LIDAR images \\
\hline
\end{tabular}

Table 1: Approaches used in geomorphological studies of desert sand dunes [3].

Paisley et al. [10] reported that Landsat visible (red) and nearinfrared spectral data can be used to effectively discriminate active and inactive sand populations in the Mojave Desert. Mohamed and Verstraeten [4] presented an advanced method based on the analysis of multi-temporal Landsat images for studying the dynamics of different dune morphologies. This algorithm, called RGB-clustering has been tested at the South Rayan Dune Field, Egypt, Namib Sand Sea, Namibia, White Sands Dune Field, USA and several other dune complexes around the world. The advantage of this methodology is that a variety of dune types, morphologies, and wind regimes can be mapped with accuracy. 
The main purpose of this study was to determine the direction and distance of annual dune migration in the Palen Dune complex located east of Joshua Tree National Park in the western Sonoran Desert of southern California and adjacent to the Riverside East Solar Energy Zone. One of the goals of the Desert Renewable Energy Conservation Plan (DRECP) developed by the Bureau of Land Management (BLM) is to conserve sand transport corridors between sand dunes and their sand sources, including upland sediment source areas [11]. These sand sources are commonly dry lakes or ephemeral rivers, and mountainous canyons with associated alluvial fans.

The general purpose of the DRECP is to conserve and manage plant and wildlife communities in the desert regions of southern California, while also facilitating the timely permitting of new renewable (solar and wind) energy facilities. The Palen Dunes complex is located within several kilometers of the Chuckwalla Solar I and the Palen Solar I energy facilities. To better understand the geophysical processes and the annual rates by which sand dunes migrate in the direction of (or away from) energy facilities, we applied the RGB-clustering method for spatial and temporal movement analysis to the Palen sand dune complex and to the Kelso sand dune complex from 1990 to 2014.

\section{Study areas}

\section{Grand falls dune field}

To apply this Landsat dune migration methodology with confidence over the dune complexes in California, we first validated the method using field measurements and analysis of sand dune movements on Navajo Nation lands of Arizona, at the Grand Falls dune field (Figure 1) from 1953 to 2010, as provided by Redsteer et al. [7]. Global positioning system (GPS) and ground-based LiDAR (light detection and ranging) measurements were used to monitor the migration rate of the sand dunes in these Navajo Nation lands.

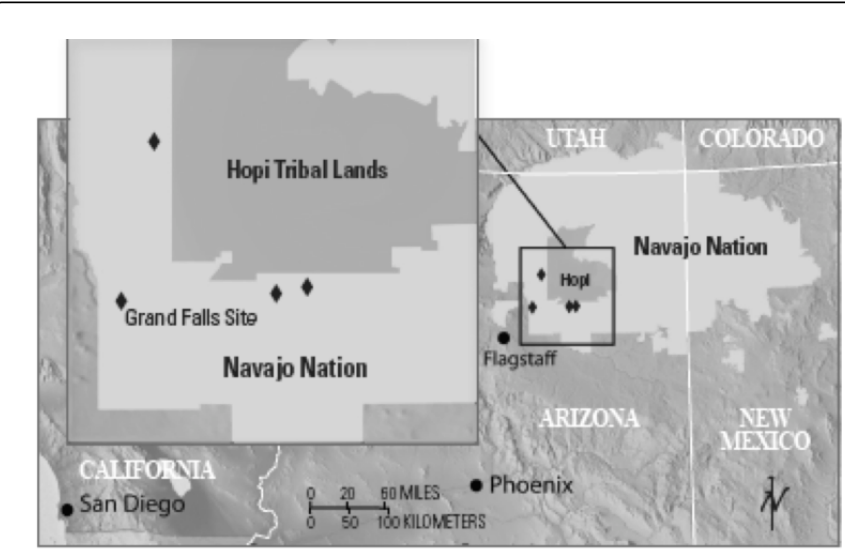

U.S. Department of the Interior

U.S. Geological Survey

Figure 1: Location of Grand Falls dune movement study site [7].

\section{Palen dunes complex}

Palen Dunes is a notable formation in the southern DRECP area that is considered a sand sink for wind and water transport pathways (Figure 2) from the Clark's Pass and Pinto Wash to the north. The Kelso dune field is also a terminus for another sand path generated by the Mojave River [12], flowing north from the San Bernardino Mountains and then turning abruptly just west of Barstow, to proceed east through Afton Canyon and forming a $55 \mathrm{Km}$ long sand sheet known as Devil's Playground that supplies a source of sand [13]. Prior to this Landsat analysis, sand dynamics of removal and accumulation in this dune formation had not been mapped over time, despite its close proximity of less than $5 \mathrm{Km}$ to development sites in the East Riverside Solar Energy Development Zones (SEZs) in the case of Palen Dunes and a proposed utility-scale solar installation on the west of Soda Mountain in San Bernardino, County.

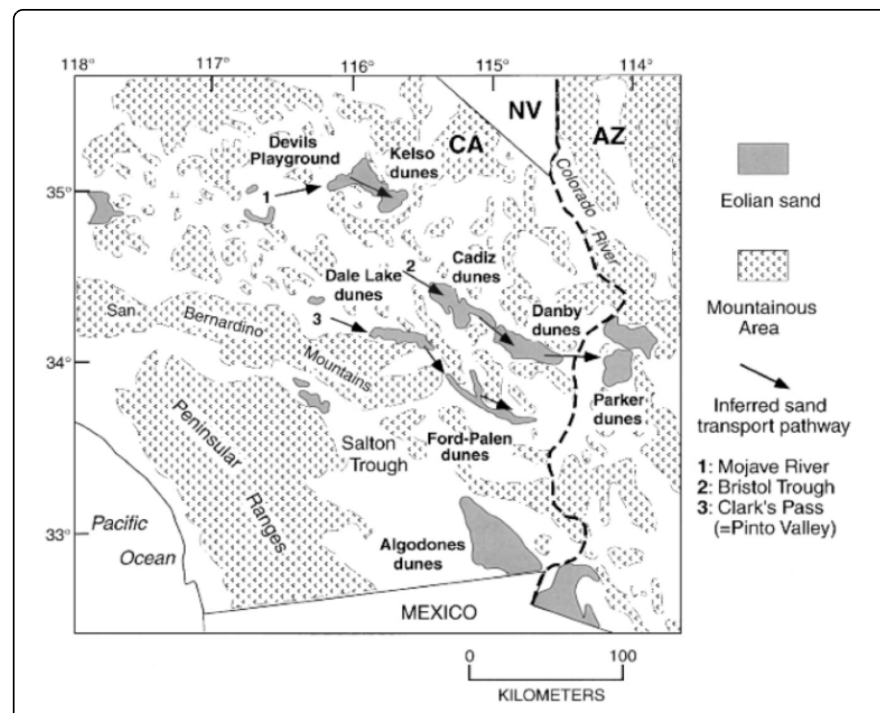

Figure 2: Sand transport pathways in the eastern Mojave and western Sonoran Deserts.

\section{Kelso dune field}

Kelso Dunes $\left(34.92^{\circ} \mathrm{N},-115.77^{\circ} \mathrm{W}\right)$ is located in the eastern Mojave Desert of southern California (Figure 2), 50 miles west of the Nevada border and $130 \mathrm{Km}$ from the Riverside East SEZ and the Palen dune field. They are part of the formation called Devils Playground [13], in a valley rimmed on the south, east, and north by the Granite, Providence, and Kelso mountains respectively [12,14]. A northprojecting spur of the Bristol Mountains only partly blocks the western side, leaving a gap through which wind-blown sand can enter from the northwest.

\section{Methods}

\section{Multi-temporal Landsat-TM imagery}

Landsat Thematic Mapper (TM) 5 and 8 image data sets were acquired from the USGS Earth Explorer (http:// earthexplorer.usgs.gov/) and processed with Standard Terrain Correction (Level 1T). A first set of Landsat TM5 images (Table 2) were selected to correspond (as closely as possible) to the measurement periods of Grand Falls dune field studies by [7].

The criteria used in all Landsat image selection were as follows:

- Best available radiometric, geometric, and atmospheric quality; 
Citation: Potter C, Weigand J (2016) Analysis of Desert Sand Dune Migration Patterns from Landsat Image Time Series for The Southern

Page 3 of 8

- Sun direction of a TM scene was perpendicular to the dune crest or at the stoss side (Figure 3), and the sun elevation angle was greater than $30^{\circ}$.

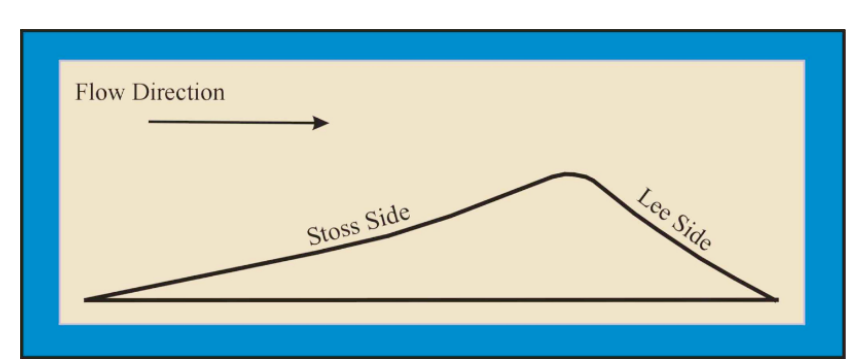

Figure 3: Diagram of stoss and lee sides of a sand dune [18].

\begin{tabular}{|l|l|l|l|}
\hline \multicolumn{1}{|c|}{$\begin{array}{c}\text { Acquisition } \\
\text { Date }\end{array}$} & Image ID & Sun Azimuth & Sun Elevation \\
\hline $07 / 4 / 1984$ & $\begin{array}{l}\text { LT50370351984186PAC } \\
00\end{array}$ & 108.82 & 60.96 \\
\hline $08 / 27 / 1992$ & $\begin{array}{l}\text { LT50370351992240XXX } \\
02\end{array}$ & 125.63 & 51.71 \\
\hline $06 / 22 / 1997$ & $\begin{array}{l}\text { LT50370351997173XXX } \\
02\end{array}$ & 108.75 & 62.04 \\
\hline $08 / 31 / 2005$ & $\begin{array}{l}\text { LT50370352005243PAC } \\
01\end{array}$ & 135.78 & 54.75 \\
\hline $08 / 13 / 2010$ & $\begin{array}{l}\text { LT50370352010225PAC } \\
01\end{array}$ & 128.08 & 59.26 \\
\hline
\end{tabular}

Table 2a: Landsat images list used for the mapping of Grand Falls sand dune migration.

\begin{tabular}{|l|l|l|l|}
\hline $\begin{array}{c}\text { Acquisition } \\
\text { Date }\end{array}$ & Image ID & $\begin{array}{l}\text { Sun } \\
\text { Azimuth }\end{array}$ & $\begin{array}{l}\text { Sun } \\
\text { Elevation }\end{array}$ \\
\hline 30-Sep-1990 & LT50380361990273XXX03 & 138.15 & 43.71 \\
\hline 30-Sep-1990 & LT50380371990273XXX02 & 136.87 & 44.60 \\
\hline 20-Aug-1990 & LT50390361990232XXX03 & 119.48 & 53.35 \\
\hline 3-Jul-1990 & LT50390371990184XXX03 & 101.23 & 59.61 \\
\hline 12-Sep-1990 & LT50400361990255XXX01 & 130.44 & 48.45 \\
\hline 12-Sep-1990 & LT50400371990255XXX01 & 128.83 & 49.17 \\
\hline 9-Sep-2000 & LT50380362000253XXX02 & 135.00 & 51.83 \\
\hline 9-Sep-2000 & LT50380372000253XXX02 & 133.28 & 52.65 \\
\hline 16-Sep-2000 & LT50390362000260XXX02 & 138.25 & 49.99 \\
\hline 16-Sep-2000 & LT50390372000260XXX02 & 136.69 & 50.88 \\
\hline 22-Aug-2000 & LT50400362000235XXX03 & 126.09 & 55.95 \\
\hline 22-Aug-2000 & LT50400372000235XXX03 & 123.94 & 56.57 \\
\hline 5-Sep-2010 & LT50380362010248EDC00 & 137.02 & 54.70 \\
\hline 5-Sep-2010 & LT50380372010248PAC01 & 135.16 & 55.57 \\
\hline
\end{tabular}

\begin{tabular}{|l|l|l|l|}
\hline 27-Aug-2010 & LT50390362010239EDC00 & 132.62 & 56.93 \\
\hline 15-Nov-2010 & LT50390372010319PAC01 & 156.46 & 34.74 \\
\hline 3-Sep-2010 & LT50400362010246EDC00 & 136.06 & 55.22 \\
\hline 3-Sep-2010 & LT50400372010246EDC00 & 134.16 & 56.06 \\
\hline 2-Oct-2014 & LC80380362014275LGN00 & 151.75 & 48.03 \\
\hline 2-Oct-2014 & LC80380372014275LGN00 & 150.55 & 49.16 \\
\hline 23-Sep-2014 & LC80390362014266LGN00 & 148.47 & 50.91 \\
\hline 9-Oct-2014 & LC80390372014282LGN00 & 152.86 & 46.91 \\
\hline 30-Sep-2014 & LC80400362014273LGN00 & 151.06 & 48.68 \\
\hline 30-Sep-2014 & LC80400372014273LGN00 & 149.83 & 49.80 \\
\hline
\end{tabular}

Table 2b: Landsat image list for the mapping of Southern California desert sand dunes.

\section{Image data calibration}

Calibration to compensate for radiometric errors from sensor defects, variations in scan angle, and system noise, resulted in images that represented true spectral radiance. ENVI 5.0 reads parameters (e.g., gains, offsets, solar irradiance, sun elevation, and acquisition time) from the Landsat MTL file (Level-1 metadata). Reflectance was computed using the following equation:

$$
\rho_{\lambda}=\frac{\pi{ }_{\lambda} d^{2}}{E S U N_{\lambda} \sin \theta}
$$

Where:

$$
L_{\lambda}=\text { Radiance in units of } \frac{W}{m^{2} \times s r \times u m}
$$

(e.g., watts per square meter per steradian when $\lambda$ the wavelength is given in $\mu \mathrm{m}$ )

$\mathrm{d}=$ Earth to sun distance, in astronomical unit (au, 1 au is equal to $149.6^{\star} 10^{\wedge} 6 \mathrm{Km}$, or $2.956^{*} 10^{\wedge} 6 \mathrm{mi}$ )

ESUN $\lambda=$ Solar irradiance in units of $\mathrm{W} /\left(\mathrm{m}^{2^{*}} \mathrm{um}\right)$

$\theta=$ Sun elevation in degrees

\section{Atmospheric correction}

Atmospheric corrections included adjustments to account for Rayleigh scattering, gaseous absorption, and aerosol scattering in three visible channels $(480 \mathrm{~nm}, 560 \mathrm{~nm}$, and $660 \mathrm{~nm})$, and the near-infrared (NIR) channel $(830 \mathrm{~nm})$. Atmospheric constituents such as water vapor and ozone are extracted from climatology data sets, while aerosol optical depths (AODs) are derived from the Landsat $5 \mathrm{TM}$ scene itself by adopting the dark target approach.

The FLAASH version used included the following features:

- Correction for the adjacency effect (pixel mixing due to scattering of surface-reflected radiance)

- An option to compute a scene-average visibility (aerosol/haze amount) for handling the presence of clouds and stress-inducing atmospheric conditions, such as cirrus and opaque cloud 
Citation: Potter C, Weigand J (2016) Analysis of Desert Sand Dune Migration Patterns from Landsat Image Time Series for The Southern

classification map and adjustable spectral polishing for artifact suppression.

FLAASH starts from a standard equation for spectral radiance at a sensor pixel, L, that applies to the solar wavelength range (thermal emission is neglected) and flat, Lambertian materials or their equivalents. The equation applied was as follows:

$$
L=\left(\frac{A \rho}{1-\rho_{e} S}\right)+\left(\frac{B \rho_{e}}{1-\rho_{e} S}\right)+L_{a}
$$

Where:

$\rho=$ the pixel surface reflectance

$\rho_{\mathrm{e}}=$ an average surface reflectance for the pixel and a surrounding region

$\mathrm{S}=$ the spherical albedo of the atmosphere

$\mathrm{La}=$ the radiance back scattered by the atmosphere

$\mathrm{A}$ and $\mathrm{B}$ are coefficients that depend on atmospheric and geometric conditions, but not on surface conditions.

\section{Bi-temporal layer stacking}

The approach of a Bi-Temporal Layer Stacking (BTLS) has its origin from Write Function Memory Insertion (WFMI) methods first presented by Jensen [15]. WFMI is a visual change-detection technique, where single bands from multi-temporal satellite images are displayed in specific colors (typically red, green and blue-RGB (see Figure 4). Mohamed and Verstraeten [4] applied WFMI to multitemporal Landsat images to detect the dynamics of sand dune movement (Figure 5).

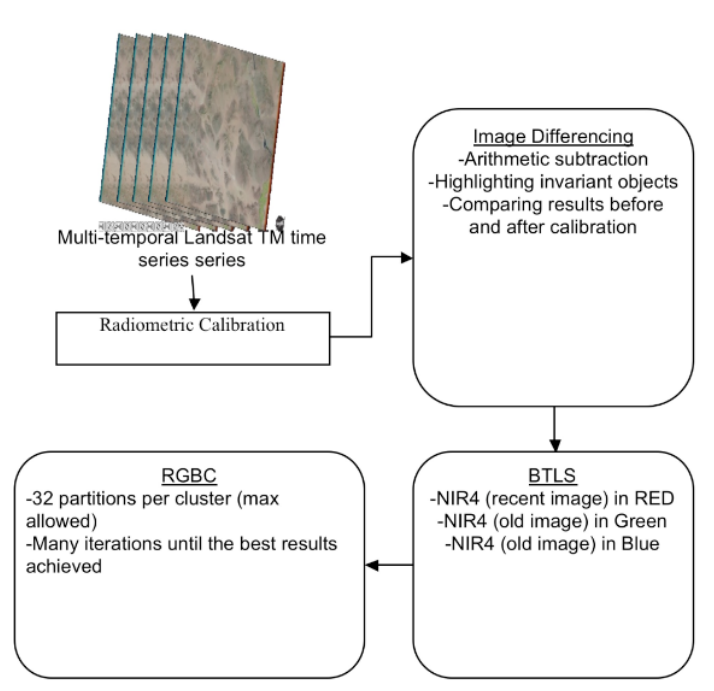

Figure 4: Processing scheme for sand dune movement mapping with Landsat images.

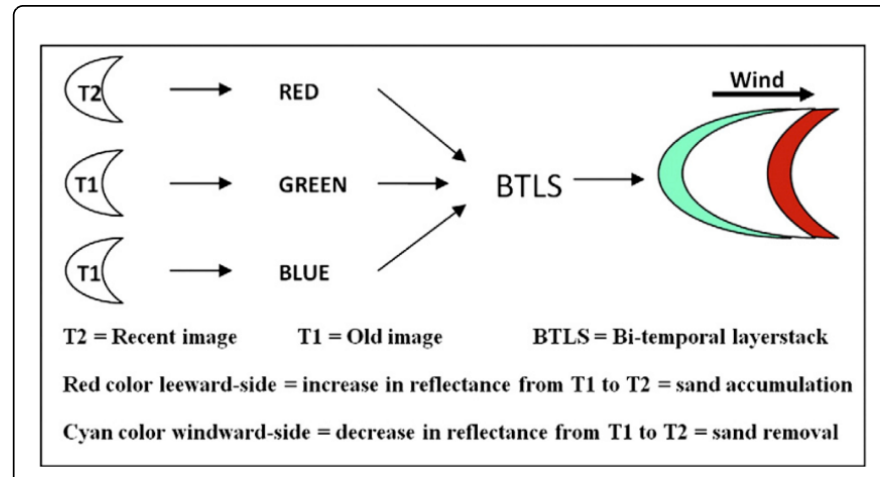

Figure 5: Illustration of bi-temporal layer stacking (BTLS) for detecting dune migration [4].

\section{RGB-clustering}

RGB-clustering methodology was used to compress three bands of data into one and to perform simple unsupervised classification (Figure 6). The RGB-clustering method is more specialized than the commonly applied Self-Organizing Data Analysis Technique (ISODATA) algorithm because it uses three-band, 8-bit data [16].

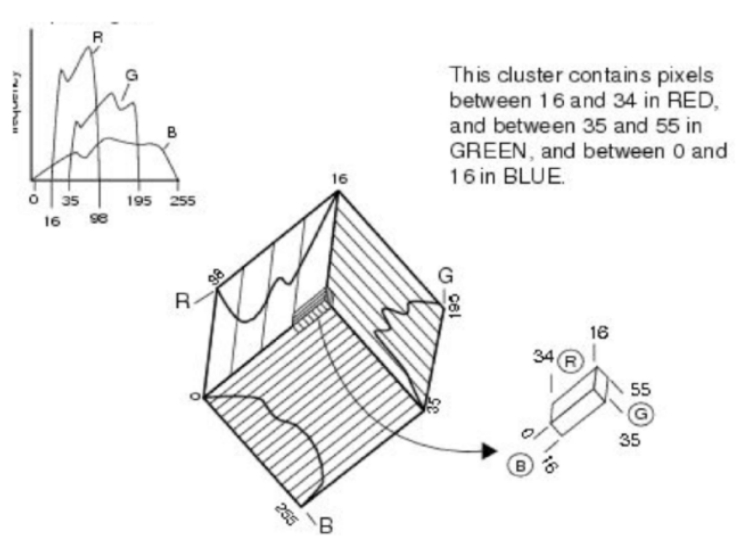

Figure 6: Schematic diagram of the RGB clustering methodology.

\section{Results and Discussion}

\section{Grand Falls dune movement validation}

Using the BTLS approach with Landsat TM images, we estimated the migration rate and direction of the Grand Falls dune field from 1984 to 2010. The post-event NIR band was displayed in the red color to express the increase in reflectance levels (Figure 7). The pre-event NIR band was displayed in both the green and blue channels to represent the stoss side of the sand dune in a cyan color (i.e., a decrease in reflectance levels) [17]. 


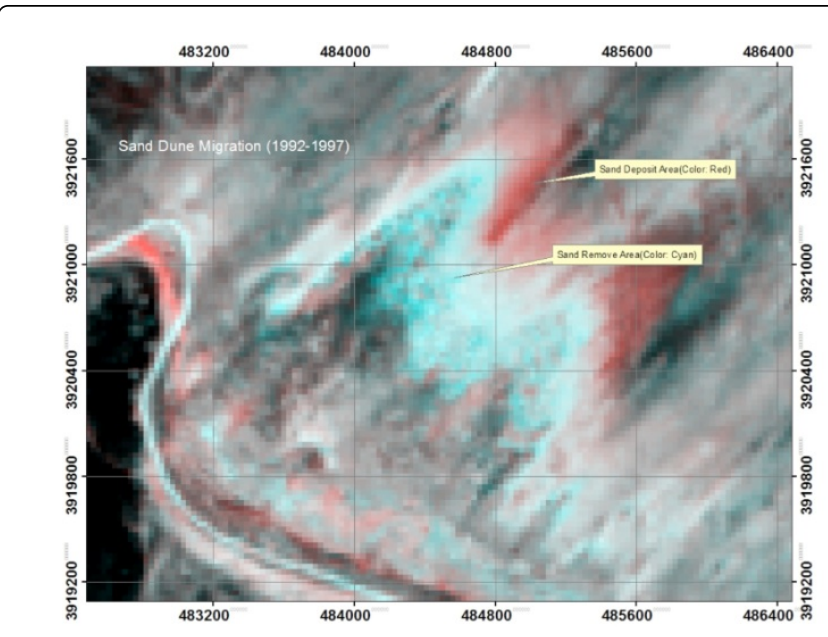

Figure 7: BTLS map results of Grand Falls dune field on the Navajo Nation.

By adjusting the RGB classes during clustering, the pixels representing sand movement were matched to Landsat BTLS maps. The new raster layer from RGB-clustering was used to estimate the migration rates of dunes in the Grand Falls dune field from 1992 through 2010. We noted that Landsat pixels located on the southwest corner of the dune field were misclassified as sand. This area was covered by riparian or wetland vegetation. The RGB-clustering approach cannot correctly discriminate this land cover type from sand erosion and deposition areas. Therefore, a Landsat vegetation/barren mask layer should be applied before the RGB-clustering method is used on a larger desert region for dune migration mapping.

To evaluate the results from BTLS and RGB-clustering against field measurements of dune movements from the USGS [7], we created more than 1600 dot pairs of vertices along the four leading dune edge lines (1992, 1997, 2005, and 2010) for comparison to measured migration distances. The leading edges from USGS measurements were considered the baselines in this comparison of dot pairs and Euclidian distances of Landsat-estimated leading edges (Figure 8). Results showed that the predominant SW-to-NE direction of sand dune movements was the same between the USGS measurements and processed Landsat image results. The smallest average difference between dot pairs was found for the 2005 leading dune edge i.e., at less than $1 \mathrm{~m}$ difference (Table 3). Among the other comparison years, the largest difference between dot pairs occurred in 2010 at an average of $50 \mathrm{~m}$, which are still less than a 2 pixel width error in the $30 \mathrm{~m}$ resolution Landsat TM images. The leading edge for 1992 detected from Landsat imagery was the only edge lagging behind the leading edge delineated by USGS measurements by an average of $46 \mathrm{~m} \mathrm{[18].}$

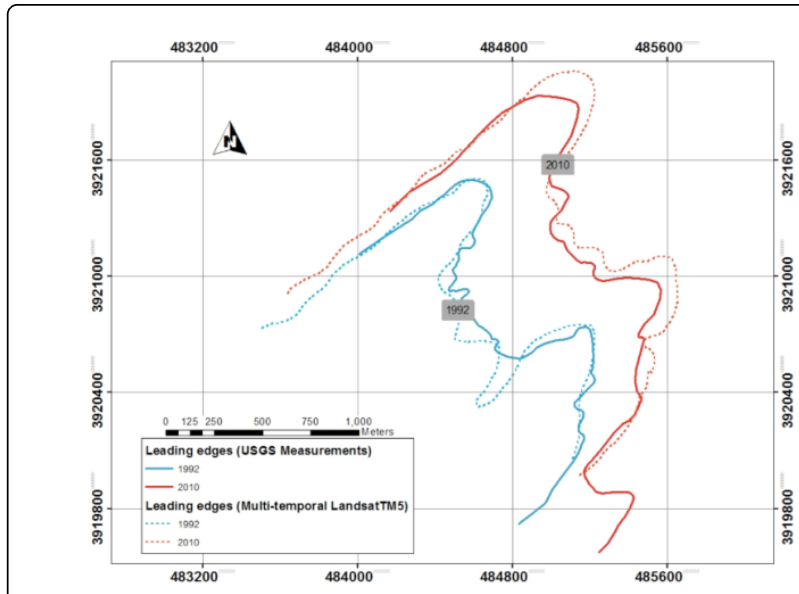

Figure 8: Comparisons of sand dune migration rates between RGBclustering algorithm results and USGS measurements of dune leading edges.

\begin{tabular}{|l|l|l|l|l|l|}
\hline & Dot Pairs & Max $(\mathbf{m})$ & Min $(\mathbf{m})$ & Average $(\mathbf{m})$ & Std Dev \\
\hline $\mathbf{2 0 1 0}$ & 517 & 151.80 & -64.85 & 50.15 & 48.58 \\
\hline $\mathbf{2 0 0 5}$ & 399 & 58.69 & -174.64 & 0.08 & 34.68 \\
\hline $\mathbf{1 9 9 7}$ & 388 & 131.70 & -64.85 & 39.73 & 53.20 \\
\hline $\mathbf{1 9 9 2}$ & 390 & 59.08 & -294.76 & -45.62 & 82.40 \\
\hline
\end{tabular}

Table 3: Leading edge differences between dot pairs of Landsat RGBclustering and USGS measurements of sand dune migration at Grand Falls Navajo Nation, Arizona.

Comparisons of Landsat-estimated maximum dune migration rates in the Grand Falls dune field with measured rates established from USGS field data showed that USGS-measured maximum migration rates were $20-60 \%$ lower than the Landsat-estimated distances during all periods (except the 1997-2005 time period (Table 4). The closest match of maximum annual dune migration rates between the two methods were found for the 1997-2005 time period and over the entire 1992-2010 period, at less than $15 \mathrm{~m}$ difference, which is less than onehalf the width of a Landsat TM pixel. The overall difference between the Landsat image and USGS measurement results in maximum dune migration rates between 1992 and 2010 was about 145 meters, which is equivalent to five Landsat pixels, compared to an equivalent of nearly 25 pixel distances detected in this overall (18 year) maximum migration distance [19].

\begin{tabular}{|l|l|l|l|l|}
\hline \multirow{2}{*}{ Time period } & \multicolumn{2}{|l|}{ Distance between two leading edges $(\mathbf{m})$} & \multicolumn{2}{l|}{ Annual migration-rate $\left(\mathbf{m} \mathbf{y r}^{-1}\right)$} \\
\cline { 2 - 5 } & USGS & Landsat & USGS & Landsat \\
\hline $1992-1997$ & 156 & 260 & 31.2 & 52.0 \\
\hline $1997-2005$ & 355 & 249 & 44.4 & 31.1 \\
\hline $2005-2010$ & 105 & 253 & 21.0 & 50.6 \\
\hline
\end{tabular}


Citation: Potter C, Weigand J (2016) Analysis of Desert Sand Dune Migration Patterns from Landsat Image Time Series for The Southern California Desert. J Remote Sensing \& GIS 5: 164. doi:10.4172/2469-4134.1000164

Page 6 of 8

\begin{tabular}{|l|l|l|l|l|}
\hline $1992-2010$ total & 616 & 762 & 34.2 & 42.3 \\
\hline
\end{tabular}

Table 4: Comparison of maximum migration rates in the Grand Falls dune field.

There are several possible explanations for the modest differences detected between Landsat image results and USGS measurements of sand dune migration in the Grand Falls dune field. First, the exact dates of the leading edges delineated by USGS researchers were not known to us. One winter/spring windy season may cause the dune fields to migrate more than $30 \mathrm{~m}$. Because most of the Landsat images used in this study were captured in the cloud-free summer period, the timing of the satellite images and USGS measurements may be mismatched seasonally. Next, the spatial resolution of Landsat images is coarser than the $1 \mathrm{~m}$ resolution measurements surveyed by USGS investigators. Therefore, an average error level of just under two $30 \mathrm{~m}$ Landsat pixels would not be unexpected. Finally, the 30-50 m level of spatial accuracy in dune migration rates from 1992 to 2010 may be accounted for by unavoidable shading effects of the leading edges of sand dunes captured by Landsat images [20].

\section{Palen dunes sand migration patterns}

Landsat reflectance values along three evenly spaced profile sampling lines (Figure 9) were extracted from a time-series of Landsat image dates acquired from 1985 to 2014. Results imply that dunes were most actively shifting in 2014, and were the least active in 1995 (Figure 10), in terms of overall movement (removal and accumulation) along these selected profile lines. The NIR band difference between these two years was largest moving toward the center of the dune on the profile lines [21].

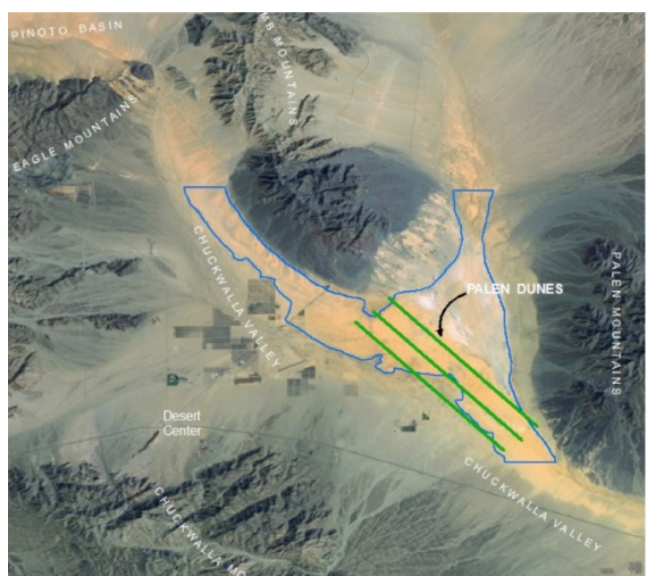

Figure 9: Palen Dunes (in blue boundary outline) true-color satellite image with three profile sampling lines shown in green.

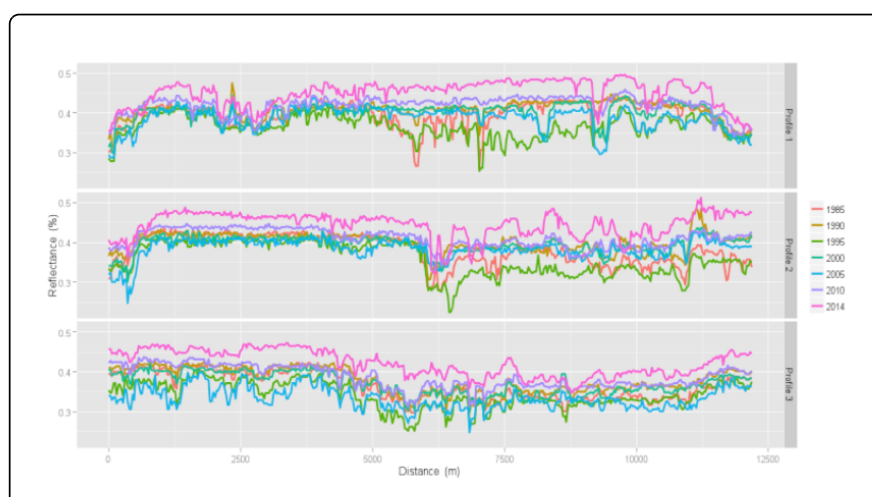

Figure 10: Change in surface reflectances between 1995 and 2014 in the Landsat NIR band along three profile lines in Palen dunes.

Yearly maps of Palen sand dune dynamics [Figure 11(a,b)] showed consistent areas of stable dune surfaces, as well as consistent sand removal and accumulation zones. The consistent areas of stable dune surfaces were located at the northern-most point adjacent to the Pinto Wash $\left(33.79^{\circ} \mathrm{N},-115.28^{\circ} \mathrm{W}\right)$ and along the southern central margin $\left(33.73{ }^{\circ} \mathrm{N},-115.24^{\circ} \mathrm{W}\right)$, adjacent to Lower Big Wash. Consistent sand removal zones were located on the extreme northwestern side and along the southern margin of the dune formation. Consistent sand accumulation zones were located all along the central interior sections of the dune formation and on the southeastern extreme.

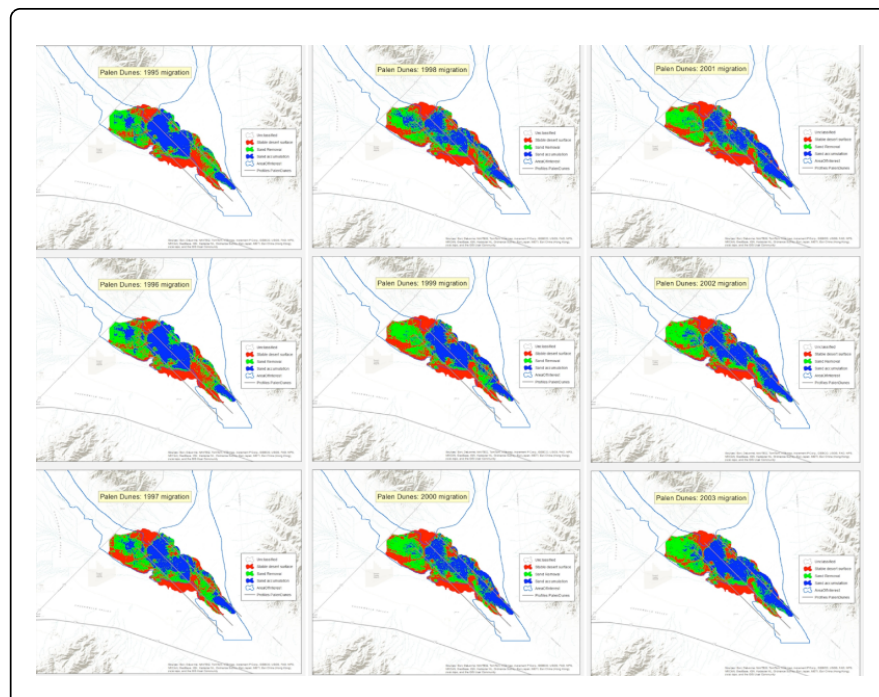

Figure 11a: Time-series maps of Palen sand dune migration, generated from Landsat RGB clustering results. 


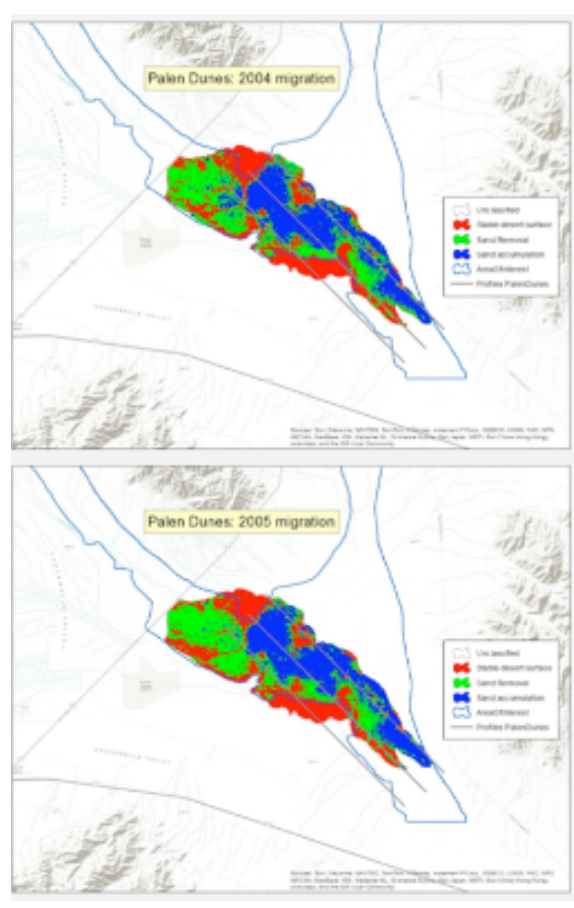

Figure 11b: Time-series maps of Palen sand dune migration, generated from Landsat RGB clustering results.

In 2014, the area covered by stable dune surfaces was estimated at $6.6 \mathrm{Km}^{2}$, whereas sand removal zones were estimated to cover 12.1 $\mathrm{Km}^{2}$ and sand accumulation zones were estimated to cover $25.5 \mathrm{Km}^{2}$. In comparison, the resulting dune map from 1995 showed that the area covered by stable dune surfaces was $14.1 \mathrm{Km}^{2}$, whereas sand removal zones covered $15.6 \mathrm{Km}^{2}$ and sand accumulation zones covered 15.4 $\mathrm{Km}^{2}$. A broader visualization of the 2014 Palen Dunes sand dynamics was generated for Figure 12, showing sand removal areas that originated in the Palen Valley washes (around $33.89^{\circ} \mathrm{N},-115.22^{\circ} \mathrm{W}$ ) to the north of the main dune formation, feeding into the central Palen sand accumulation zones.

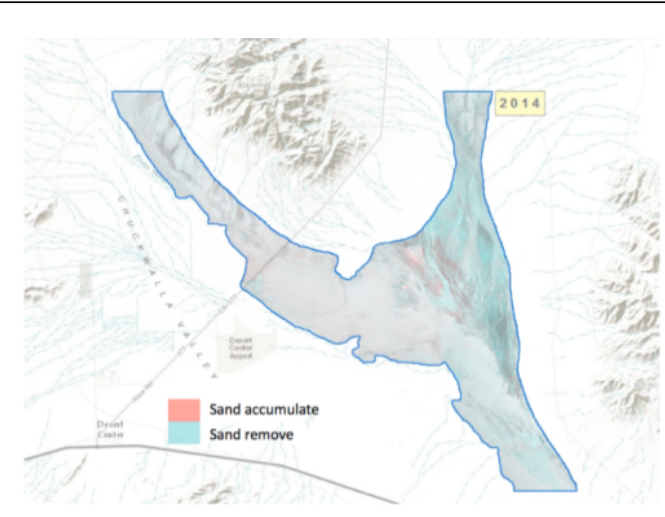

Figure 12: Composite of Palen dunes (in blue boundary outline) sand dune dynamics between 2010 and 2014.
Based on these Landsat analysis results, the leading edge of the Palen sand accumulation zone has shifted by less than $0.1 \mathrm{Km}$ in the southeast direction between 1995 and 2014 (Figure 13). The leading edge of sand accumulation in 2014 remained $2 \mathrm{Km}$ distant from the Chuckwalla Solar I facility to the south of the Palen Dune formation and remained $3 \mathrm{Km}$ distant from the Palen Solar I facility to the southeast.

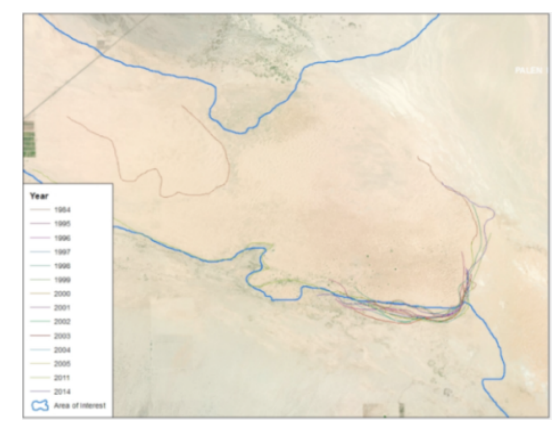

Figure 13: Map of the leading edges of Palen sand dune vectors from 1995 through 2014.

According to results from Landsat BLTS and RGB clustering approaches, the rate of Palen dune migration in active regions has been variable over time and space, depending in part on the recent history of vegetation cover. Around 1984, many sand fields on Palen Dunes were separated by scattered bush and desert grass cover. Most active dune areas were covered by a thin sand sheet. Only the main dune fields were totally covered by what appeared to be deep sand. By 2011, Palen dune coverage interpreted from Landsat 5 TM images suggested that the two separate sand sheets had become connected and covered most of the areas that had scattered vegetation in 1984 .

We estimated Palen sand dune migration rates as high as $50 \mathrm{~m}$ per year (1373 $\mathrm{m}$ in 27 years, 1984-2011), predominantly in the southern direction, depending on the locality. The overall size of active dune fields increased significantly from 1984-2011. Image analysis suggested that the Palen Dunes had grown in areal extent by $47 \%$ (from $31 \mathrm{Km}^{2}$ to $45 \mathrm{Km}^{2}$ ) over the past three decades. Active dune areal extent expanded $60 \%$ (from $21.3 \mathrm{Km}^{2}$ to $34.12 \mathrm{Km}^{2}$ ) over the same time period. The area covered by scattered bush decreased from $9.2 \mathrm{Km}^{2}$ to $7.5 \mathrm{Km}^{2}$.

Despite these sand migration dynamics detected across Palen Dunes, no active threats to energy facilities at Chuckwalla Solar I and the Palen Solar I could be inferred from the results of this study. The leading edge of sand accumulation in 2014 remained 2-3 Km distance from both of these solar energy facility locations to the south of Palen Dunes.

\section{Kelso dunes sand migration patterns}

Mapping of Kelso sand dune dynamics from Landsat BTLS (Figure 14) showed large consistent areas of stable dune surfaces from 1995 to 2014. There was a narrow zone of sand accumulation detected along the western edge of Kelso Wash on the eastern margin of the Bristol Mountain range, and sparse areas of sand removal across the westerncentral section of the dune formation. Results indicated that Kelso sand dune dynamics were less active overall than the Palen dune 
Page 8 of 8

dynamics since the mid-1990s, having no distinct and changing leading edge of sand accumulation in the Kelso formation.

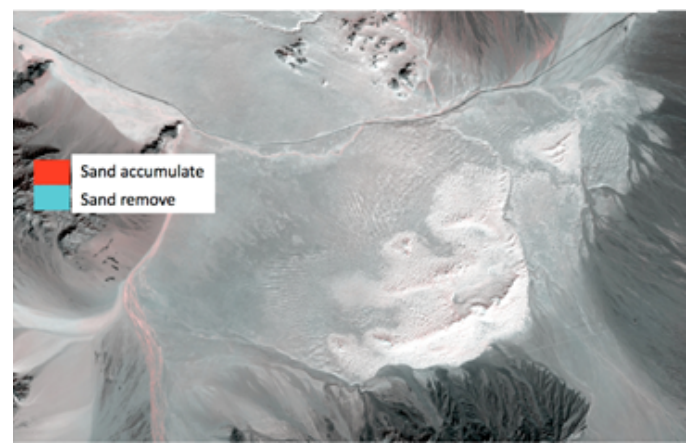

Figure 14: Kelso dunes dynamics from 1995 to 2014 generated from Landsat BTLS.

\section{Conclusions}

Integration of readily available Landsat data with ground-based data collection of aeolian sand transport rates measurements surveyed by USGS investigators from 1992 to 2010 at the Navajo Nation Grand Falls, Arizona dune complex validated the remote sensing method for characterizing dune mobility. The predominant direction of sand dune movements was correctly mapped at this site from the satellite imagery, as well as the migration distances of the leading edges of sand dunes over the entire 1992-2010 monitoring period.

Reproducibility of this remote sensing is critical for utility [2]. Application of the methodology to two dune systems in southern California demonstrated its usefulness for accurately mapping sand migration patterns and rates. Between 1995 and 2014, Palen Dunes lost over half of its stable dune surface and increased its sand accumulation zone by nearly that same area coverage. Sand removal areas mostly originated in the Palen Valley washes to the north of the main dune formation, which appeared to supply the majority of sand into the central Palen Dune accumulation zones. In contrast, changes in the dune pattern at Kelso Dunes were not apparent, perhaps due to its more constraining mountain landscape features.

These analyses have an immediate application for understanding past and future sand dune movements and characterizing potential impacts to nearby utility-scale solar energy installations, such that developers of renewable energy installations will be better able to appraise the risks to facility operations from proximity to active desert dunes in southern California over the term of energy development leases.

\section{Acknowledgements}

The authors thank USGS scientists Redsteer MH, Vogel J, and Bogle $\mathrm{R}$ for sharing sand dune migration data sets used for the Navajo Nation validation study. Satellite image processing and application of classification algorithms were carried out by Shuang Li of California State University Monterey Bay. The US Department of the Interior Bureau of Land Management funded this study.

\section{References}

1. Kocurek G, Lancaster N (1999) Aeolian system sediment state: theory and Mojave Desert Kelso dune field example. Sedimentology 46: 505-515.

2. Hugenholtz CH, Levin N, Barchyn TE, Baddock MC (2012) Remote sensing and spatial analysis of aeolian sand dunes: A review and outlook. Earth-Science Reviews 111: 319-334.

3. Livingstone I, Wiggs GFS, Weaver CM (2007) Geomorphology of desert sand dunes: A review of recent progress. Earth-Science Reviews 80: 239-257.

4. Mohamed INL, Verstraeten G (2012) Analyzing dune dynamics at the dune-field scale based on multi-temporal analysis of Landsat-TM images. Remote Sensing of Environment 119: 105-117.

5. Dong P (2015) Automated measurement of sand dune migration using multi-temporal lidar data and GIS. International Journal of Remote Sensing 36: 5426-5447.

6. Telfer MW, Fyfe RM, Lewin S (2015) Automated mapping of linear dune field morphometric parameters from remotely-sensed data. Aeolian Research 19: 215-224.

7. Redsteer MH, Bogle RC, Vogel JM (2011) Monitoring and analysis of sand dune movement and growth on the Navajo Nation, Southwestern United States: US Geological Survey Fact Sheet 2011-3085, p: 2.

8. Werner BT (1995) Eolian dunes: computer simulations and attractor interpretation. Geology 23: 1107-1110.

9. Kocurek G, Ewing RC (2005) Aeolian dune field self-organizationimplications for the formation of simple versus complex dune-field patterns. Geomorphology 72: 94-105.

10. Paisley ECI, Lancaster N, Gaddis LR, Greeley R (1991) Discrimination of active and inactive sand from remote sensing: Kelso dunes, Mojave Desert, California. Remote Sensing of Environment 37: 153-166.

11. DRECP Final EIS (2015) Desert Renewable Energy Conservation Plan (DRECP) and Environmental Impact Report/Environmental Impact Statement. Chapter III. 4. Geology and Soils, California Energy Commission, California Department of Fish and Wildlife, US Bureau of Land Management, US Fish and Wildlife Service.

12. Clarke ML, Rendell HM (1998) Climate change impacts on sand supply and the formation of desert sand dunes in the south-west USA. Journal of Arid Environments 39: 517-531.

13. Edwards SR (1993) Luminescence dating of sand from the Kelso Dunes, California. Geological Society (London) Special Publications 72: 59-68.

14. Sharp RP (1966) Kelso Dunes, Mojave Desert, California. Geological Society of America Bulletin 77: 1045-1074.

15. Jensen JR (1996) Introductory digital image processing: A remote sensing perspective. Upper Saddle River, New Jersey: Prentice Hall.

16. ERDAS (2011) Imagine 2011. Field Guide, Atlanta: ERDAS Inc., Geosystem.

17. Adler-Golden SM, Matthew MW, Bernstein LS (1999) Atmospheric Correction for Short-Wave Spectral Imagery Based on MODTRAN4. In Summaries of the Eighth Annual JPL Earth Science Workshop, p: 1.

18. Hansen EC, Bodenbender BE, Johnson BG, Kito K, Davis AK, et al. (2011) The Origin of Dark Sand in Eolian Deposits along the Southeastern Shore of Lake Michigan. The Journal of Geology 119: 487-503.

19. Hermas ES, Leprince S, El-Magd IA (2012) Retrieving sand dune movements using sub-pixel correlation of multi-temporal optical remote sensing imagery, northwest Sinai Peninsula, Egypt. Remote Sensing of Environment 121: 51-60.

20. Jacobberger PA (1989) Reflectance characteristics and surface processes in stabilized dune environments. Remote Sensing of Environment 28: 287-295.

21. Leprince S, Barbot S, Ayoub F, Avouac J (2007) Automatic and precise orthorec-tification, coregistration, and subpixel correlation of satellite images, application to ground deformation measurements. IEEE Transactions on Geoscience and Remote Sensing 45: 1529-1558. 